\title{
The 'Marketplace' - a novel conference teaching and learning model
}

To the Editor: The word 'marketplace' brings to mind a bustling, colourful place where shoppers come to browse goods. The range of items on offer may vary from week to week and from market to market, but is usually led by one principle: what do the shoppers around here want to buy? The same principle of supplying a need can be applied to the 'purchase' of knowledge at medical conferences. However, most conferences tend to offer solely didactic lectures with little opportunity for meaningful direct interaction between the delegates and experts/speakers.

Over the past few years, I have run a novel and highly popular teaching and learning event called the Paediatric Marketplace at the Emergency Medicine Society of South Africa conferences in Cape Town. The central idea is to have a dynamic, fun, interactive session based on a market-style environment, where delegates (shoppers) browse and chat with experts (stallholders), who tailor their teaching to individual needs.

Between ten and twelve market-stalls are set up on any topics of interest (e.g. cardiopulmonary resuscitation, triage, intraosseous line insertion, the 'blue baby', fluid management in children, cervical spine immobilisation, foreign body removal techniques, childhood poisoning, etc.). The stalls have eye-catching and inviting materials such as posters, interactive cases, quizzes, video material, radiology images, etc. Mannequins and/or equipment to demonstrate skills are available where appropriate. Delegates are free to browse at their own pace, and they will naturally stop and spend time at stalls that interest them.

In June this year the Paediatric Marketplace was invited to 'go global' with a large-scale event at the International Federation of Emergency Medicine (IFEM) Conference in Hong Kong (ICEM 2014). Our expert stallholders were members of the IFEM Paediatric 
Emergency Special Interest Group (PEMSIG), and the co-organiser was Dr Ffion Davies (PEMSIG Chair). The event was a huge success, and it became clear that this innovative teaching and learning experience would be replicated at other conferences globally.

I would like to make a plea to those who may organise these events in the future to please respect and honour the integrity and ethos of the original concept by maintaining two core features:

- Senior/expert stallholders. All stallholders need to be authorities or experts in their field. Delegates must be able to ask their 'curved-ball', burning or esoteric questions and receive meaningful, intelligent and expert answers. Junior staff and trainees, while invaluable as stall-assistants, are not appropriate solo stallholders as they are not able to adequately answer unexpected or unusual queries or assist all levels of delegates.

- Not for profit. A further core feature (and perhaps an ironic one) is that the Marketplace is entirely non-commercial. No one is selling anything for money or profit. Expertise, skills and knowledge are being shared purely to help others in the field. The trade is very much 'two-way', with meaningful exchange of accrued experience, wisdom and ideas between experts and delegates.

The Marketplace session is a vibrant, novel and interactive conference event where experts tailor their teaching to the needs of the delegate. Isn't this what all learners in the education marketplace want?

\section{Baljit Cheema}

Paediatric Emergency Specialist, Division of Emergency Medicine, Faculty of Health Sciences, University of Cape Town, South Africa baljit.cheema@uct.ac.za

S Afr Med J 2014;104(10):651-652. DOI:10.7196/SAMJ.8820

\section{Correction}

In the article 'Mammographic screening for breast cancer in a resource-restricted environment', which appeared on pp. 294-296 of the April 2014 SAMJ, and the reply to the letter by Pitcher $e t$ al. entitled 'Mammography reporting at Tygerberg Hospital, Cape Town, South Africa' on pp. 456-457 of the July issue, the authors should have been listed as J P Apffelstaedt and K Baatjes. 